\title{
Orígenes de la Plástica en la Escuela de Arquitectura de la Universidad de Chile: Parraguez, Dvoredsky y Galván**
}

\author{
Origins of Visual Arts in the School of Architecture at Universidad de Chile: \\ Parraguez, Galvan and Dvoredsky
}

\section{<Resumen>}

La enseñanza de la Plástica tuvo un papel central en las reformas universitarias en Chile. Este texto presenta el proceso en que se desarrollaron las reformas a la Escuela de Arquitectura de la Universidad de Chile en las décadas del treinta y cuarenta.

CPALABRAS CLAVE>

ESCUELA DE ARQUITECTURA UNIVERSIDAD DE CHILE / REFORMA UNIVERSITARIA / PLÁSTICA / ARTE ABSTRACTO / PROYECTO

\section{<KEYWORDS >}

SCHOOL OF ARCHITECTURE AT UNIVERSITY DE CHILE / UNIVERSITY REFORM \& VISUAL ART \& ABSTRACT ART I PROJECT
En la primera mitad del siglo xx la cultura en torno a las artes visuales y los problemas derivados de la forma no tuvieron en Chile una tradición que las situara en una posición de avanzada en relación a otras manifestaciones paralelas que surgieron en el contexto sudamericano.

A diferencia de los conocidos alcances en el ámbito de la literatura, el vuelo emprendido en paralelo en Chile por el arte abstracto no figurativo, su traspaso conceptual hacia los criterios de orden y composición de la nueva arquitectura y la proyección de esas ideas hacia la formación académica y la práctica profesional, tardó más en levantarse y posicionarse como corriente o escuela, a pesar de lo tempranas que pueden ser vistas sus primeras apariciones en el contexto de la región.

No sólo en la particularidad de sus manifestaciones y en lo intermitente de su proceso de formación, sino en el debate que se instala a raíz del surgimiento de los colectivos de artistas y arquitectos plásticos formados en las décadas del treinta y cuarenta $y$, en especial, en la cristalización de esas ideas en las reformas a las escuelas de arquitectura de la Universidad de Chile y de la Universidad Católica en la segunda mitad de la década del cuarenta, donde la plástica y el entrenamiento visual encontraron una posición vertebral en la práctica y discurso arquitectónico.

\footnotetext{
Arquitecto y máster en Arquitectura Tulane University. Diploma de Estudios Avanzados doctorado en Proyectos Arquitectónicos ETSAB-UPC. Desde 2005 es académico e investigador en la Escuela de Arquitectura de la Universidad Diego Portales. Ha escrito artículos y ha presentado ponencias sobre arquitectura moderna tanto en Chile como en el extranjero. Ha sido Editor de Arquitectura de la revista CA y Coordinador Editorial de la revista ARQ. Es coautor del libro RESIDENCIAS MODERNAS: HABITAR COLECTIVO EN EL CENTRO DE SANTIAGO 1930-1970, Ediciones UDP, 2009.

* Este artículo es un resumen parcial de un capítulo de la tesis doctoral en curso «Alberto Piwonka: en el cruce de las ideas de la modernidad en Chile» que se realiza actualmente para la Escuela Técnica Superior de Arquitectura de Barcelona.
} 
Este trabajo pretende relacionar una secuencia de hechos que se vinculan directa o indirectamente a las aulas de la Escuela de Arquitectura de la Universidad de Chile y que se sucedieron en el proceso de asimilación de las ideas de las vanguardias y su traspaso gradual a la enseñanza y práctica de la Arquitectura ocurridos en las décadas del treinta y cuarenta.

\section{Раггаguez, Dvoredsky y los Decembristas}

"La notoriedad del asunto radicaba no sólo en el tono trasgresor de algunas de esas propuestas artísticas sino en su disposición a aumentar el promedio creativo a través de la innovación y el desenfado» ${ }^{1}$

La abstracción en las artes visuales pareciera entrar en Chile en forma tímida y con menor alcance que en países como Argentina y Uruguay, donde el regreso de Joaquín Torres García el año 1934, o el surgimiento hacia 1945 de la Asociación de Arte Concreto Invención y el Movimiento Madi en Argentina ${ }^{2}$, derivaron en una tradición que ha sido reconocida como una de las más variadas, completas e interesantes surgidas en la región. A pesar de ello, es sabido que en Chile, según concuerdan varios autores, se encuentra la aparición más temprana de un colectivo cohesionado de arte abstracto: el grupo conocido por el nombre de los Decembristas, que organizó probablemente la primera muestra de arte abstracto aparecida en América Latina ${ }^{3}$.

El grupo fue creado en 1933 bajo la influencia, patrocinio y liderazgo del poeta Vicente Huidobro y contaba entre sus miembros con algunos estudiantes de la Escuela de Arquitectura de la Universidad de Chile, como Waldo Parraguez Ortiz y José Dvoredsky Roitman, y las artistas María Valencia y Gabriela Rivadeneira Rodríguez. El grupo giraba en torno a un círculo de intelectuales que era cercano al poeta. De hecho, Valencia era la mujer del músico

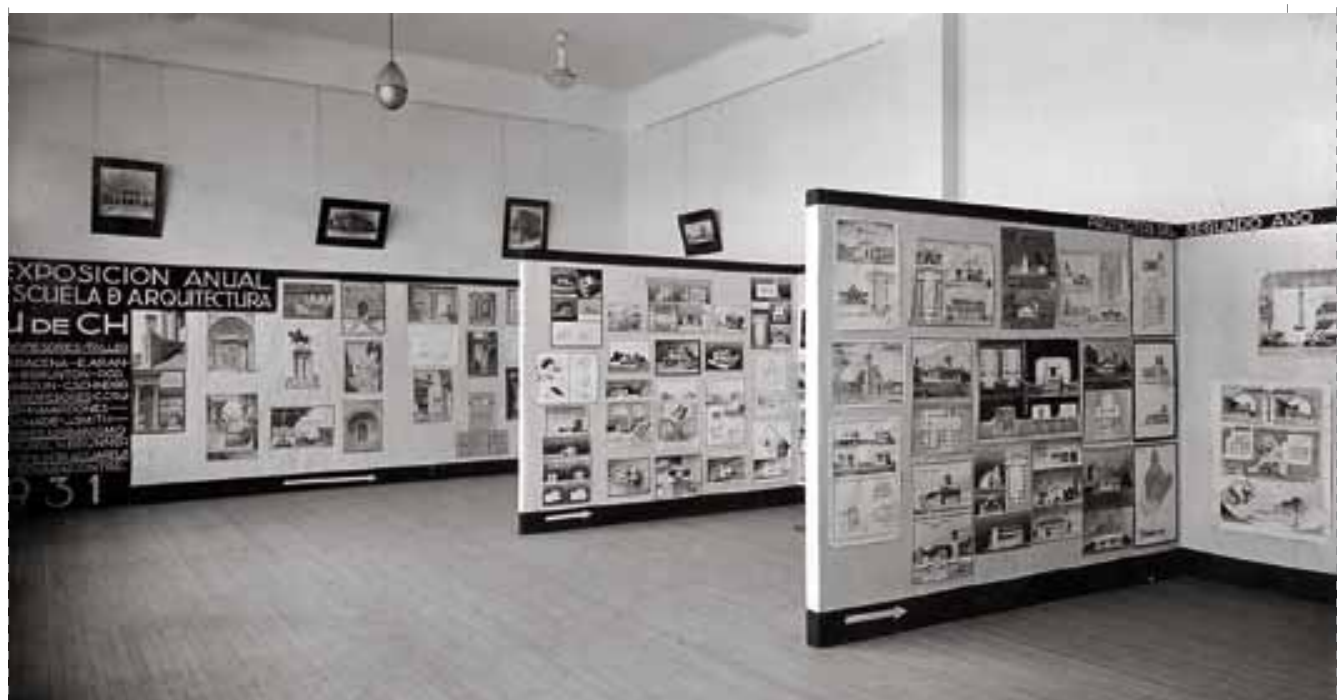

Archivo de Originales FADEU-PUC.

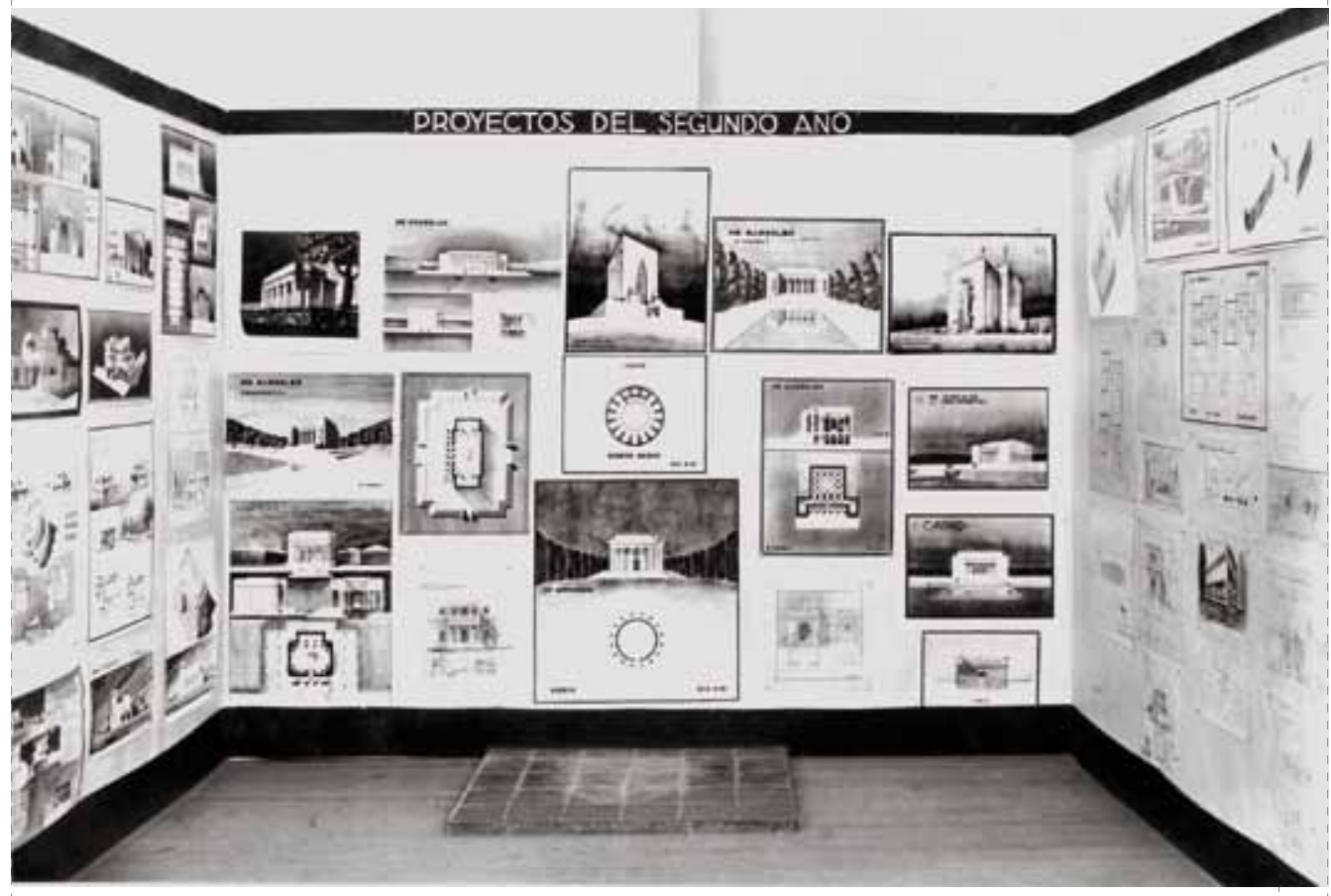

Archivo Enrique Pérez Castelblanco.

Cáceres, Gonzalo. Op. Cit. En «Nexos olvidados en la historia de la vanguardia chilena: de los Decembristas a la revista ARQuitectura». Revista ARQ N 33, agosto de 1996. Una completa aproximación a estos acontecimientos está detallada en la tesis doctoral de Alejandro Crispiani «Objetos para transformar el mundo: trayectorias del arte concreto invención: la Escuela de Arquitectura de Valparaíso y las teorías del diseño para la periferia (Argentina y Chile, 1940-1970)», leída en 2008 en la Universidad de Quilmes en Argentina.

Los estudios de Gonzalo Cáceres, Miguel Rojas Mix, Patricio Lizama y Alejandro Crispiani coinciden en situar la exposición de 1933 de los Decembristas, como la primera de arte abstracto o concreto realizada en América Latina. Al día siguiente de la inauguración de la Exposición de Diciembre una nota aparecida en el diario El Mercurio ya se refiere al grupo con el nombre de los Decembristas. Ver diario El Mercurio del 20 de diciembre de 1933. Mayores antecedentes sobre los Decembristas pueden ser recogidos en los ensayos de Rojas Mix, Miguel. «Vicente Huidobro y el arte abstracto», en la revista Araucaria de Chile № 32 cuarto trimestre de 1985 y «Vicente Huidobro y el arte abstracto ¿0 concreto?, en El Mercurio, suplemento Artes y Letras de 13 de julio de 1997, en el de Lizama, Patricio «Juan Emar y Vicente Huidobro: recuerdo y vigencia» en Monasterios P., Elizabethy Lastra, Pedro (Eds). Con tanto tiempo encima: aportes de literatura latinoamericana en homenaje a Pedro Lastra. Plural Editores, Bolivia, 1997, y en los textos antes citados de Gonzalo Cáceres y Alejandro Crispiani. 


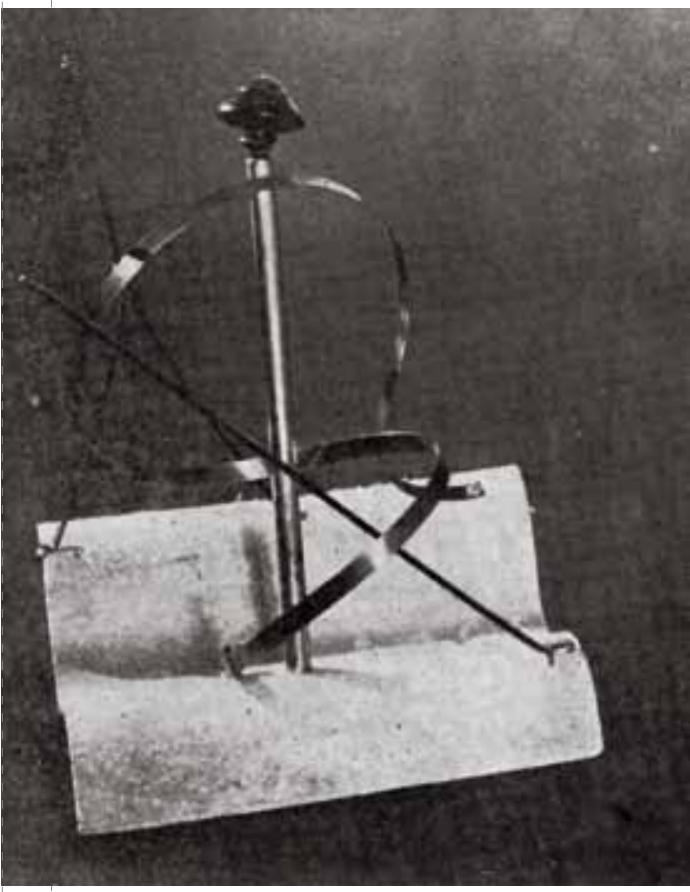

Catálogo Exposición de diciembre, 1933 Fotografía de Antonio Quintana.
«Total extraarmónico», Waldo Parraguez.

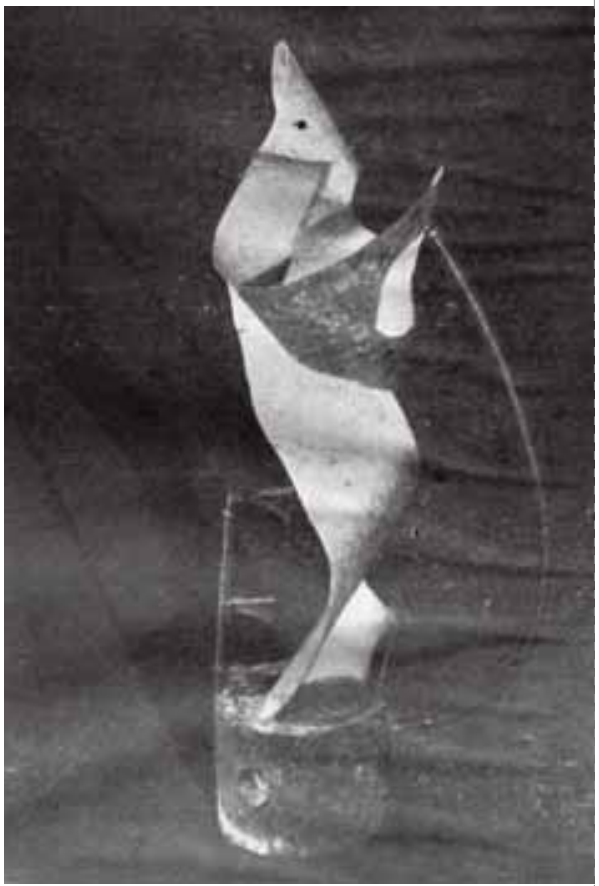

Revista ARQuitectura No 1, 1935 Fotografía de Antonio Quintana.
Eduardo Lira Espejo y Rivadeneira estaba casada en segundas nupcias con el escritor y pintor Juan Emar, amigo cercano de Huidobro y célebre por instalar en Chile en forma temprana una tribuna de difusión de las vanguardias artísticas y arquitectónicas desde sus columnas de arte en el diario LA NACIÓN ${ }^{4}$. Parraguez y Dvoredsky parecen haber sido convencidos personalmente por el poeta en la exposición de Arte Moderno de la Federación de Estudiantes realizada en noviembre de ese mismo año $0^{5}$. Desde ese momento, Dvoredsky empezará a firmar sus trabajos bajo el seudónimo de Jaime Dvor y
Parraguez iniciará una fecunda producción de construcciones plásticas. En 1934 se sumará al grupo Carlos Sotomayor Román, quien había iniciado en 1932 estudios de arquitectura en la Universidad de Chile, pero que se había trasladado de manera interna a estudiar en la Escuela de Bellas Artes de la misma universidad. Hacia 1935 se incluirá extraoficialmente, sin el beneplácito completo del grupo, al poeta peruano César Moro en una exposición montada en Lima. La presencia de Moro provocó, sin embargo, las diferencias que acabarían con la experiencia Decembrista, debido a una fuerte disputa personal de éste con Huidobro, que terminará en graves acusaciones mutuas ${ }^{6}$.

\section{La Exposición de Diciembre}

Las escasas imágenes que existen de las construcciones plásticas de los Decembristas demuestran implícitamente una continuidad ideológica y formal con el trabajo de Lázló Moholy-Nagy en su curso «Vorkurs» de la Bauhaus. Es significativo recalcar que los ejercicios de los Decembristas serán, posiblemente, las primeras asimilaciones realizadas en Chile de la producción plástica derivada de la Bauhaus, aunque éstas hayan sido recogidas de manera intuitiva por sus autores y hayan tardado años en trasladarse al ámbito académico y en formar parte consciente de los planes de estudio de las escuelas de Arquitectura, tanto en la Universidad de Chile como en la Universidad Católica.

A pesar de las pocas imágenes publicadas en el primer catálogo, en que sólo se ilustran cuatro de las cuarenta obras presentadas, en ellas es posible discernir el universo formal que se presentaba en la primera exposición? Las obras fotografiadas por Quintana muestran la irreverencia de Valencia, Rivadeneira, Dvoredsky (Dvor) y Parraguez, en un repertorio de pinturas, esculturas y construcciones plásticas que comparten un lenguaje abstracto no figurativo ${ }^{8}$.

Rivadeneira se aproximaba al problema del espacio desde la relación entre varios elementos dispuestos en equilibrio en una composición asimétrica, y parafraseando a la crítica aparecida en la revista Hoy con posterioridad a la exposición, con un indudable sentido del color y las proporciones ${ }^{9}$. La serie llamada Metal de Dvoredsky será realizada en forma sistemática por esos años, encauzando la idea de la composición abstracta a partir de

4 Emar, quien en realidad era Álvaro Yáñez, era hijo de Eliodoro Yáñez quien era el fundador y propietario del diario La Nación por esos años. Una visión completa de su trabajo en la crítica del arte y la arquitectura se encuentra en Lizama, Patricio. «Escritos de Arte: (1925-1929) / Jean Emar». Dirección de Archivos y Museos y Instituto Barros Arana, 1992.

5 Ver Parraguez, Waldo. «Ensayo sobre plástica moderna» en revista ARQuitectura № 1 de 1935.

6 Los textos de Rojas Mix (1985) y Cáceres (1996) abordan de manera más completa la efímera existencia del grupo. En el libro «Amour à Moro: homenaje a César Moro» se recogen algunos alcances de la polémica. En una nota escrita en Santiago el 23 de mayo de 1935 Parraguez señaló «Declaro no pertenecer a ningún grupo. A la exposición de Lima, en que el eje era un señor Moro, fui presentado sin mi conocimiento. Ni me molesta, ni me agrada. En cuanto a las aseveraciones calumniosas del señor Moro respecto de Vicente Huidobro, no puedo hacerme solidario por ningún motivo». Además se recoge una carta de Gabriela Rivadeneira a María Valencia: «Señora María Valencia. María: He Sabido: $1^{\circ}$ Que por intermedio tuyo participo en una exposición en Lima. $2^{\circ}$ Que tal exposición encubre un ataque a nuestro amigo Vicente Huidobro. No se me ha consultado. Que por mi voluntad exponga o no exponga, ataque o no ataque, bien. Pero que se me haga exponer y que esta exposición implique una deslealtad de la que no participo, justamente a quien apadrinó nuestra primera exposición, es inaceptable. Te pido no olvides para otra ocasión la fórmula que exige consultar al autor antes de tomar iniciativas sobre sus obras. Y cuando se trate de política turbia o desleal, descuéntame de antemano de entre tus colaboradores. Gabriela Rivadeneira...» Ver Estela, Carlos y Padilla, José Ignacio. «Amour à Moro: homenaje a César Moro». Lima, 2003. p. 98.

La primera exposición del grupo se inauguró el 19 de diciembre de 1933, la segunda el 12 de septiembre de 1934, la tercera fue montada en Lima, Perú en mayo de 1935 y la cuarta en agosto de 1935. Esta última exposición coincide con la aparición del primer número de ARQuitectura.

8 Ver catálogo Exposición de diciembre: María Valencia, Gabriela Rivadeneira, Jaime Dvor, Waldo Parraguez. Diciembre, 1933.

9 Ver revista Hoy del 27 de diciembre de 1933. pp. 40-42. 


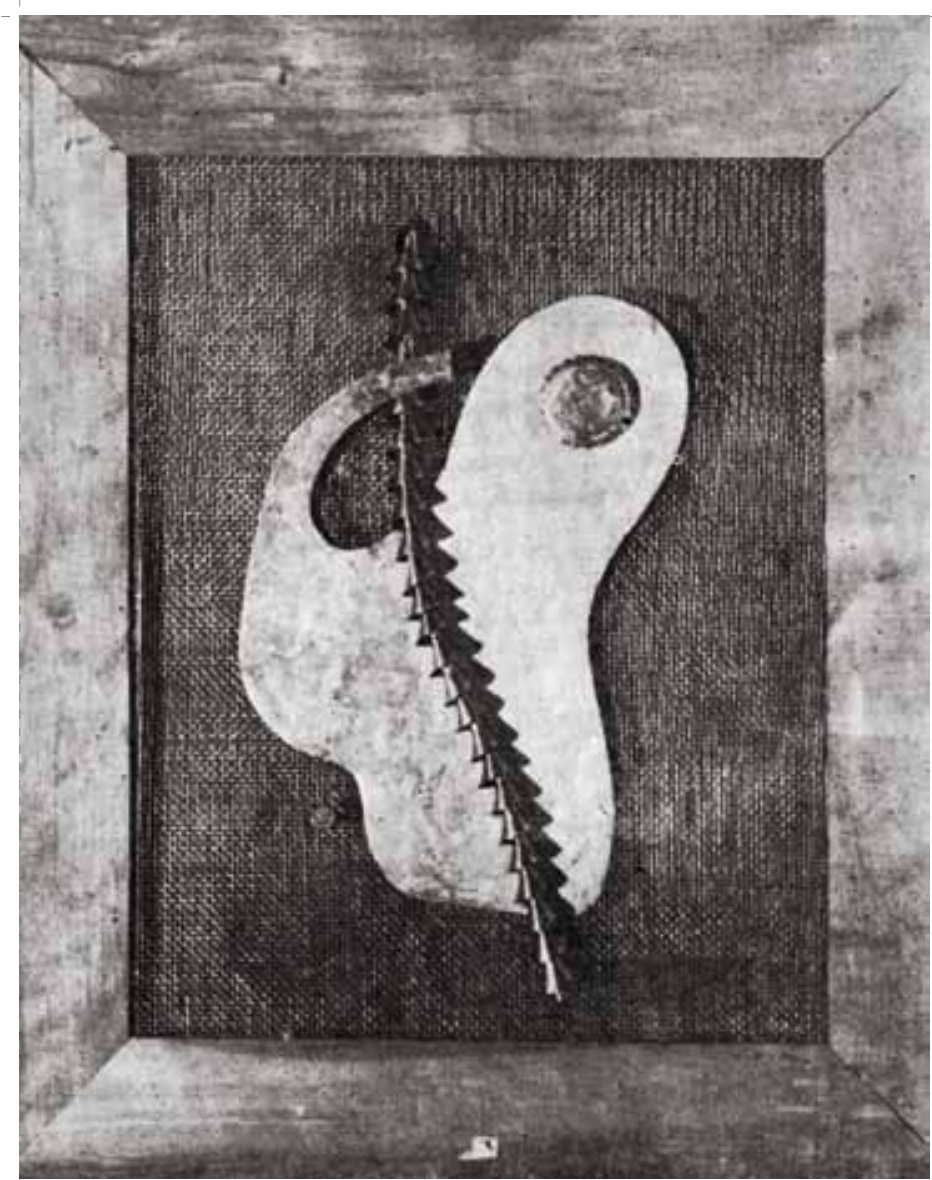

Catálogo Exposición de diciembre, 1933

Fotografía de Antonio Quintana.

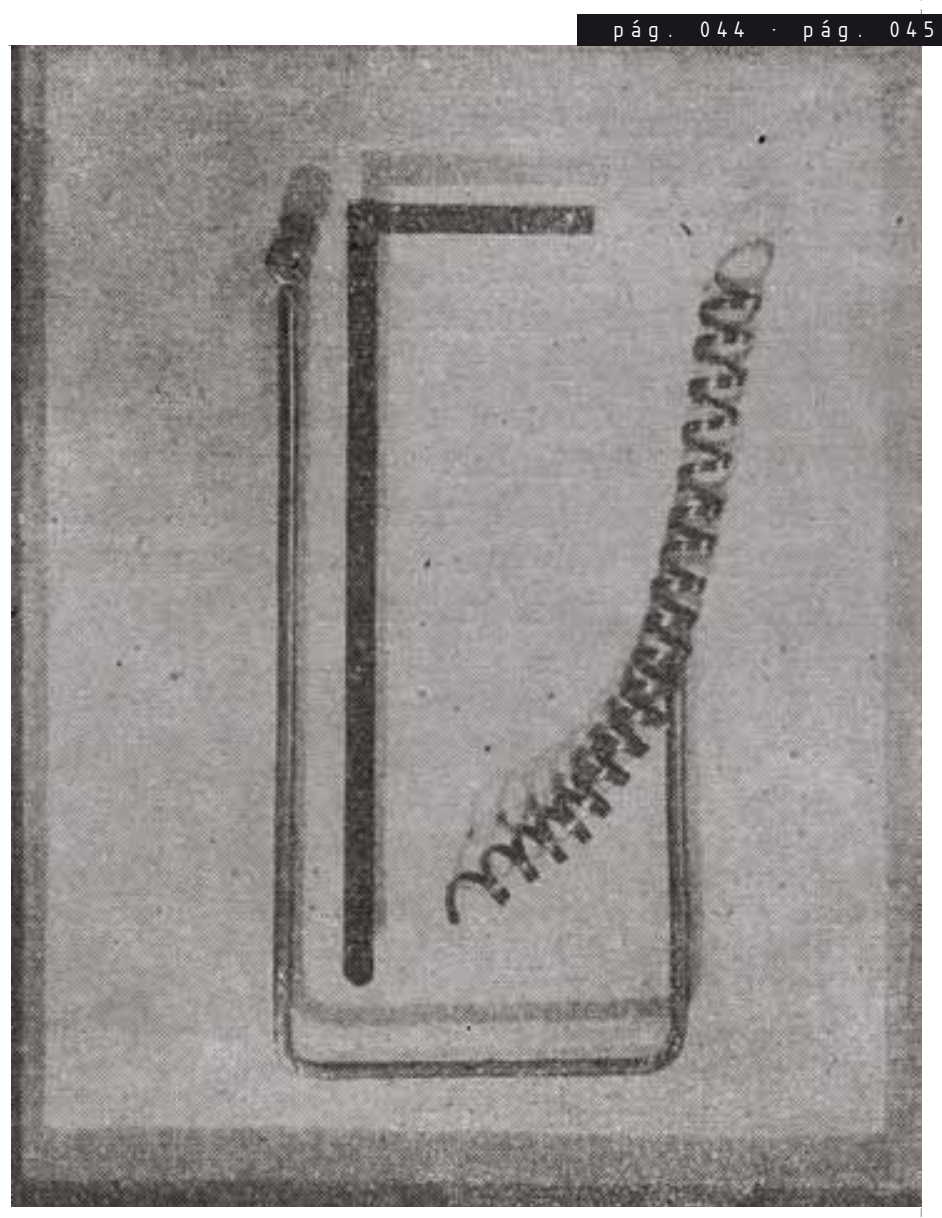

Revista Pro: Revista de Arte Nº 2, noviembre de 1934 Fotografía de Antonio Quintana. la superposición de no más de tres elementos reciclados sobre un soporte o bastidor con límites definidos. La misma publicación se refiere al trabajo de Dvoredsky como ejercicios que «les da formas espaciales, líneas insólitas, armonías, proporciones, colores desconcertantes» ${ }^{10}$, y asigna un lugar destacado a la producción plástica de Waldo Parraguez señalando que «el más extraño de los cuatro Decembristas, el que más admiraciones y condenaciones ha conquistado es Waldo Parraguez. Sus materiales de trabajo son aún más desconcertantes que los de sus compañeros. Inventariémoslos: frascos de cristal, aisladores eléctricos, alambres, barritas metálicas, trozos de discos de gramófono, pedazos de mica, tornillos, etc. (cuántas cosas caben en éstas, etc.) »11. La obra titulada CAÍDA de Parraguez, representa la aproximación más cercana entre las presentadas a la construcción del espacio, transgrediendo los límites del soporte y creando una composición tridimensional, anunciando el camino que se seguirá en años posteriores en los talleres preliminares de Plástica en las principales escuelas de arquitectura en Chile.

\section{Los impresos y revistas}

Junto al asombro y desconcierto que generaban en el público las exposiciones del grupo, Huidobro y los Decembristas irrumpieron en la escena santiaguina a través de la creación de varios impresos y revistas. Dvoredsky junto al músico Eduardo Lira Espejo dirigieron la revista PRO: REVISTA DE ARTE en sus únicos números de septiembre y noviembre de 1934, revista donde el propio Huidobro y su amigo Joaquín Torres García redactaron artículos y se publicaron nuevos trabajos plásticos de Valencia y Dvoredsky. Más definida en sus contenidos fue la ya célebre revista ARQUITECTURA (1935-1936), la cual fue pionera en el compromiso con las ideas y el discurso más acérrimo de la

\footnotetext{
10 Ídem.

12 Ver Parraguez, Waldo. «Ensayo sobre plástica moderna». ARQuitectura N 1, 1935.
}

arquitectura moderna. La revista fue creada por el propio Parraguez junto a Enrique Gebhard Paulus, su amigo y compañero en la Escuela de Arquitectura como directores, y Mario Antonioletti Randolini como gerente a cargo de materializar el proyecto. Además de servir de plataforma para el discurso de la modernidad y publicar textos fundamentales de arquitectura de esos años, ARQUITECTURA presentó un significativo interés por el arte abstracto. En su primer número se incluye un extenso ensayo de Parraguez sobre la plástica moderna, que fue ilustrado con diagramas e imágenes de las construcciones plásticas del grupo Decembrista. Parraguez planteaba que lo real era una expresión tergiversada de la realidad, en cambio lo abstracto provocaba en el receptor incomprensión y vacío, por lo tanto provocaba la reflexión necesaria en torno a la obra de arte ${ }^{12}$

No es de extrañar que entre los Decembristas se contara con la singular presencia de ambos estudiantes de arquitectura, deseosos de innovar en la práctica de la profesión y producir cambios metodológicos en la enseñanza. De hecho Parraguez parece haber sido uno de los primeros en iniciar un movimiento en ese sentido, cuando encabezó 


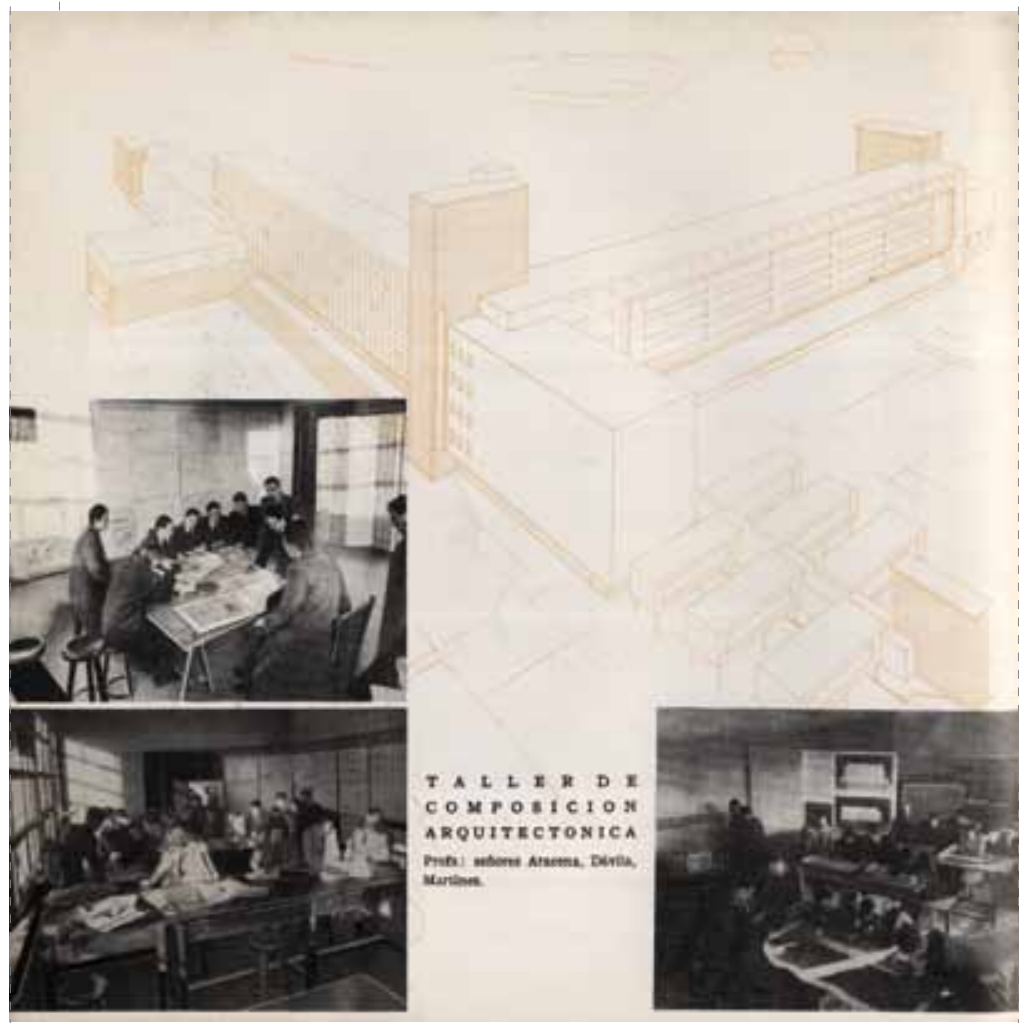

Talleres de Composición Arquitectónica. Universidad de Chile 1892-1942. p. 68.

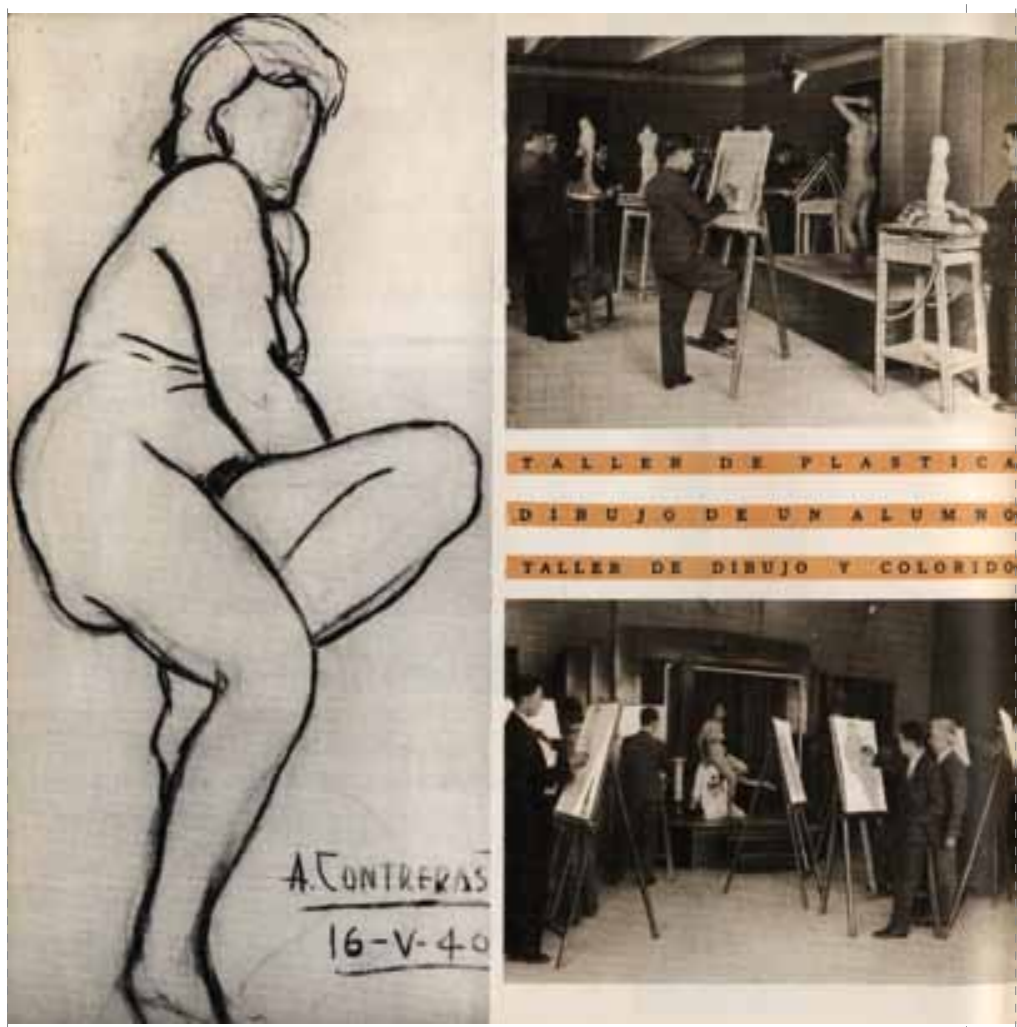

Talleres de Plástica y Dibujo y Colorido. Universidad de Chile 1892-1942. p. 66 algunas acciones dirigidas a la revisión de la enseñanza en la Escuela de Arquitectura de la Universidad de Chile en $1929^{13}$. Es más, el mismo año de la formación del grupo Decembrista, Parraguez y Dvoredsky habían sido parte del grupo de estudiantes que habían impulsado un intento de reforma a los planes de estudio de esa Escuela ${ }^{14}$.

\section{La reforma en 1933}

Dependiente de la Facultad de Ciencias Físicas y Matemáticas, la Escuela de Arquitectura estaba por esos años en una posición debilitada frente a las autoridades de la Universidad y en una situación ambigua frente a su propio quehacer docente, producto de las diferencias que generaba un plan de estudios arcaico que regirá a la escuela hasta el final del año académico de 1932. En las fotografías existentes de la exposición anual de la Escuela de Arquitectura en 1931 es posible constatar el estado de la escuela, donde los trabajos expuestos se alinean con la instrucción BeauxArts y sus técnicas de representación, a pesar de que eran visibles, aunque aisladas, algunas soluciones en sintonía con las ideas de la nueva arquitectura.

En ese ambiente académico se había posicionado en 1932 a Juan Martínez Gutiérrez como director de la Escuela de Arquitectura en medio de promesas de renovación y cambios curriculares. Es más, ese mismo año se instalará formalmente la discusión en torno a la nueva orientación de la escuela a través de una Comisión de Reforma, integrada por profesores, alumnos y ex alumnos. En ella los estudiantes fueron representados por Octavio Tinoco Chacón, Alfredo Molina Lavín, Miguel Gana Molina y Juan Borchers Fernández. Sin embargo, el intento de diálogo rápidamente fracasó y el grupo de estudiantes abandonó el trabajo de la comisión ya que según ellos se «consideró (sólo) una parte del problema por imposición del Consejo de Profesores» ${ }^{15}$, restándole validez a sus resultados. Como consecuencia del trabajo de esa comisión, se aprobó en mayo de 1933 un nuevo Plan de Estudios que será objetado por una parte importante de los estudiantes y provocará los momentos más álgidos de la reforma estudiantil. A pesar de lo meritorios que pueden ser vistos parte de sus alcances, donde se reducía la relevancia del Beaux-Arts en el currículo y se incorporaban por primera

13 Ver obituario de Waldo Parraguez en revista Arquitectura y Construcción № 10 de septiembre de 1947, p 79.

14 Más detalles de esta reforma se encuentran en el artículo de David Maulen «Experiencias docentes: inclusión / exclusión del espacio urbano y social 1933/1945/1967» fundamento» en la Estación de Biología Marina de Montemar presentada en la Pontificia Universidad Católica de Chile el año 2008.

El estado de la situación está referido en una serie de documentos que forman parte del Fondo Documental Juan Borchers del Archivo de Originales FADEU de la Pontificia Universidad Católica de Chile. 
vez los cursos de Plástica en el segundo y tercer año de la carrera, las exigencias de los estudiantes estaban lejos de cumplirse. El movimiento reclamaba la real renovación de la enseñanza en su sentido amplio, y la apertura decidida de la escuela hacia las ideas más radicales de la modernidad, promoviendo nuevos talleres y el recambio impostergable de algunos de sus profesores. De hecho, una de las exigencias fundamentales del movimiento era la renuncia del profesor de Teoría de la Arquitectura e Historia del Arte, Alfredo Benavides Rodríguez quien, según ellos sostenían, encarnaba el estado retrógrado de la enseñanza por esos años en la escuela ${ }^{16}$.

El tono de la discusión entre el Centro de Estudiantes y las autoridades se fue elevando a tal punto entre junio y agosto de 1933, que la situación fue aplacada a partir de duras sanciones impuestas a algunos de los líderes del movimiento. Como ya han indagado David Maulen o Maximiano Atria, el Consejo Universitario suspendió de clases hasta marzo de 1935 y de exámenes hasta diciembre de 1935 a algunos de los representantes del movimiento: Juan Borchers, Alfredo Molina y Francisco Aedo Carrasco. Menor fue la sanción impuesta a otros líderes del movimiento como Enrique Gebhard, Santiago Aguirre del Canto, Miguel Gana Molina, Federico Chester Murazo, Leopoldo Luisetti Martini, Raúl Véliz Montoya y Carlos Villanueva Mayo, quienes fueron suspendidos de clases hasta marzo de 1934 y de exámenes hasta diciembre de $1934^{17}$. Las sanciones destituían a la directiva completa de Centro de Estudiantes, que era presidida en 1933 por Chester, con Véliz como secretario, Gana como tesorero y Luisetti como director. Con posterioridad al conflicto cada uno de los miembros de esa directiva elevarán solicitudes ante el Consejo Universitario para anular las sanciones impuestas ${ }^{18}$. Borchers, Gebhard, Aedo, Molina, Villanueva y Aguirre del Canto no se retractarán de sus dichos y asumirán la totalidad de la sanción.

Juan Martínez parece haber sido distante de movimiento reformista. El discurso leído en agosto de 1933 por Arturo Venegas Yáñez ante la Federación de Estudiantes de la Universidad de Chile, ventilaba críticas explícitas a su labor: "El señor Martínez, que fue hace dos años una esperanza para una parte del estudiantado, pues prometía transformar radicalmente la escuela, nada ha hecho a favor de un mejoramiento efectivo; en cambio, bajo su dirección, la escuela ha alcanzado su grado máximo de desorganización ${ }^{19}$ La dirección de Martínez era percibida por los estudiantes como autoritaria, inflexible y distante del movimiento reformista. A pesar de ello el propio Martínez recomendó al Consejo Universitario suspender las sanciones hacia los estudiantes reformistas para contribuir al diálogo y a la regularización del funcionamiento de la escuela, solicitud que fue denegada por la máxima instancia de la Universidad. Las duras sanciones impuestas, la falta de entendimiento entre las partes y la escalada del conflicto derivó en la renuncia de Benavides a sus cátedras y de Juan Martínez a la dirección de la Escuela de Arquitectura, siendo reemplazado por el ingeniero Carlos Mori Ganna ${ }^{20}$. Tanto la dirección de la escuela, como el movimiento reformista y la directiva del Centro de Alumnos quedaban descabezados, lo que se traduciría en un retroceso del proceso natural de reforma y en una frustración explícita de una generación completa de estudiantes.

A pesar de ello, el movimiento de 1933 había logrado conmover el ambiente e imponer un estado de reflexión en torno a la enseñanza en la Escuela. Indirectamente, provocó, además, el ingreso de nuevos profesores que serían relevantes en la historia de la Escuela. Hacia ese año se incorporaron a la docencia arquitectos como Roberto Dávila Carson, Miguel Ángel Belloni Schiavetti y el pintor Camilo Mori Serrano. Belloni dictó las cátedras que había dejado Benavides y Mori hizo lo propio con el curso de Courtois. El retrato de la misma Escuela publicado en la REVISTA DE ARTE de la Universidad de Chile hacia 1934 presentaba con un tinte más moderno y racional el trabajo que se realizaba

16 Un completo balance de los hechos fue presentado por Juan Martínez ante el Consejo Universitario en la sesión ordinaria del 13 de septiembre de 1933. Ver Anales de la Universidad de Chile: Boletín del Consejo Universitario. Año III septiembre de 1933, $3^{\text {ra }}$ serie. pp. 17-20.

17 Ver Anales de la Universidad de Chile: Boletín del Consejo Universitario, sesión extraordinaria del 31 de agosto de 1933.

18 Tanto Chester, Luisetti y Gana elevarán la solicitud el 20 de octubre de 1933, y Véliz el 21 de noviembre del mismo año. Ver Anales de la Universidad de Chile: Boletín del Consejo Universitario de octubre y noviembre de 1933.

19 Discurso de Arturo Venegas Yáñez ante la Federación de Estudiantes leído el 7 de agosto de 1933. Este documento forma parte del Fondo Documental Juan Borchers depositado en el Archivo de Originales de la Facultad de Arquitectura de la Pontificia Universidad Católica de Chile.

20 Benavides renunciará a sus cátedras el 14 de septiembre de 1933 y Juan Martínez dejará la dirección de la Escuela de Arquitectura el 16 de septiembre del mismo año.

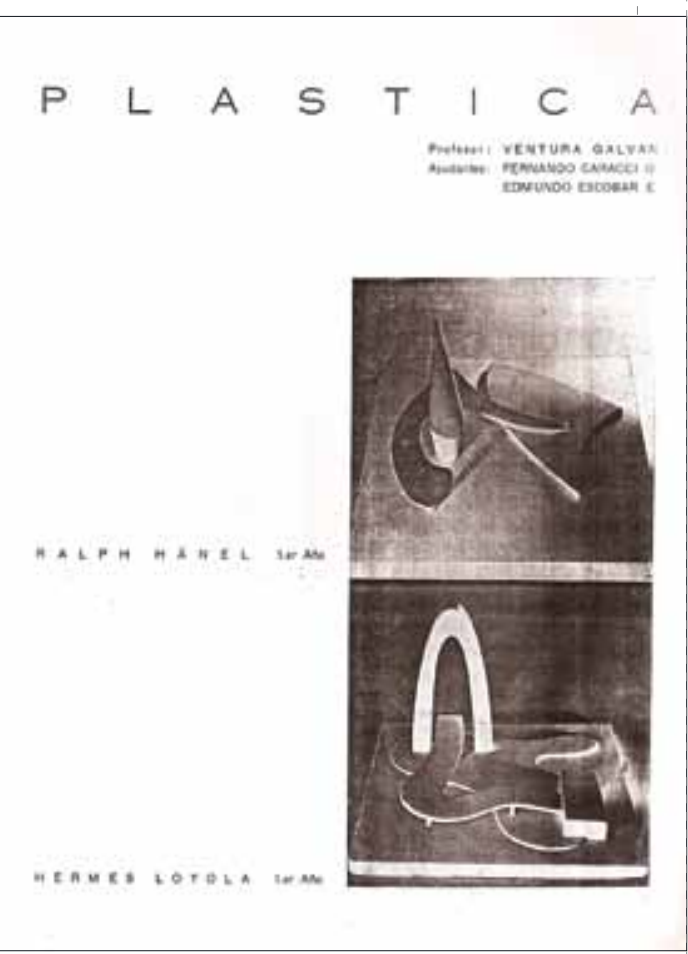

Catálogo Exposición Cincuentenario Escuela de Arquitectura Universidad de Chile 1896-1946. Universidad de Chile, 1947. p. 15

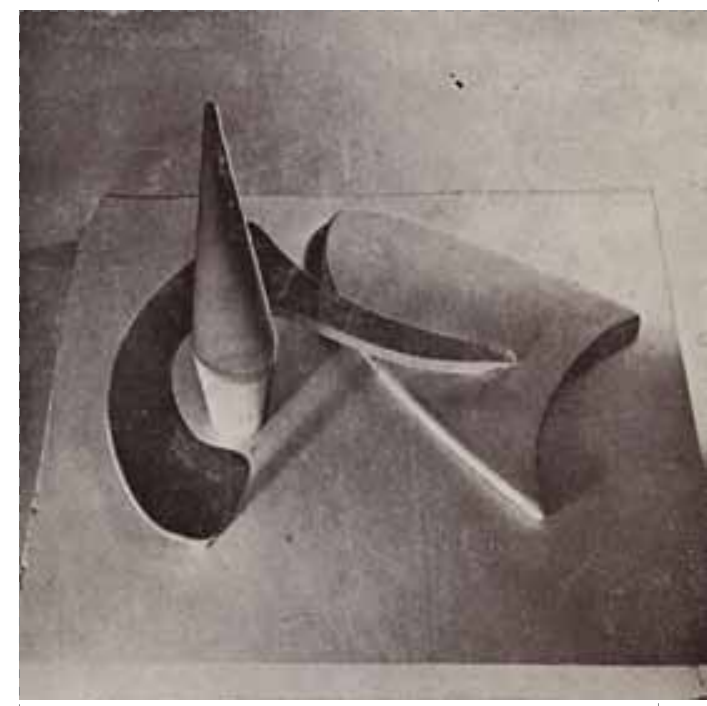

Catálogo Exposición Cincuentenario Escuela de Arquitectura Universidad de Chile 1896-1946. Universidad de Chile. 1947. Trabajo de Ralph Hanel en el curso de Plástica de Ventura Galván. 
en su interior. El ya conocido texto de Miguel Ángel Belloni que acompañó los trabajos señalaba que sus programas de estudio "han abandonado las viejas tradiciones de un academicismo arqueológico, para encauzarlos por los aspectos técnicos y plásticos adecuados a nuestra época» ${ }^{21}$. La apreciación de Belloni respecto a la marcha de la Escuela en 1934 contrastaba con la visión más radical y el espíritu renovador que buscaron fuera de la esfera universitaria varios de sus estudiantes y egresados, entre los que se contaron tanto Parraguez como Dvoredsky, así como Gebhard, Galván, Perelman o Mauricio Despouy Recart. Todos ellos se convertirían con el tiempo en actores significativos de la modernidad arquitectónica en Chile, y en líderes espirituales y asesores del movimiento de reforma que se activará hacia fines 1945 en la misma universidad, dando concreción a una parte importante de las ideas planteadas por ellos en el marco del movimiento de 1933. Hacia 1936, otro impreso, titulado ESCUELA DE INGENIERÍA Y ESCUELA DE ARQUITECTURA retratará la escuela en el funcionamiento de los talleres de Composición Arquitectónica, Plástica y Dibujo y Colorido, dando a entender que el taller de Plástica era en realidad un curso de escultura o modelado ${ }^{22}$.

Eran claramente dos las visiones, sensibilidades y criterios que se enfrentaban. La discusión superó el ámbito propio de la enseñanza y rápidamente se trasladó a las esferas propias de la práctica profesional. Posiblemente los concursos de arquitectura de esos años sean el lugar más apropiado para medir el pulso del debate. Las diferencias llegaron a su punto más álgido cuando, con motivo del fallo del concurso de la Escuela de Medicina de la Universidad de Chile en 1951 y en medio de acerbas críticas respecto al resultado, se produjo el cisma entre ambas visiones $^{23}$.

\section{La геforma en 1946}

"Hay dos historias paralelas que no se juntan totalmente pero que tienen resonancia mutua» ${ }^{24}$.
Así describía Emilio Duhart Harosteguy la analogía existente entre los procesos de reforma que se sucedieron en la segunda mitad de la década del cuarenta en las escuelas de Arquitectura de la Universidad de Chile y la Universidad Católica, fundamentales para la institucionalización de la arquitectura moderna en el ámbito de la enseñanza. En parte, gracias a que fue anterior, la reforma de 1946 en la Universidad de Chile será un referente innegable, aunque distante, para el grupo de profesores que impulsarán la reforma de 1949 en la Escuela de Arquitectura de la Universidad Católica. A diferencia de ésta que fue ideada a partir de un largo proceso de reflexión interna formulado preliminarmente por Emilio Duhart y Alberto Cruz Covarrubias hacia 1945, pero a la que rápidamente se incorporaron Alberto Piwonka Ovalle, Mario Pérez de Arce Lavín, Héctor Valdés Phillips y Sergio Larraín García-Moreno entre otros, la experiencia de la Universidad de Chile tendrá como protagonistas relevantes a los propios estudiantes. Esto no quiere decir que en el proceso vivido en la Universidad Católica la participación del Centro de Alumnos encabezado por Hernán Labarca Salazar no tuviera injerencia -bastaría recordar el incondicional compromiso de los estudiantes hacia los profesores reformistas, al ejecutar acciones fundamentales de presión, como dejar literalmente vacía la escuela en protesta por la renuncia de este grupo de profesores o la simbólica quema masiva de los manuales de vignolas ${ }^{25}$ - pero es innegable que en la Universidad Católica, la elaboración del plan surgió de una reflexión madura y consciente, a partir de los conocimientos y experiencias personales de los propios profesores reformistas. Duhart era dentro de ese grupo de profesores quien había conocido de cerca una escuela referencial como era la GSD de Harvard. Como es conocido ahí Duhart había sido cercano a Walter Gropius, Marcel Breuer y asistió a clases y conferencias de MoholyNagy, György Kepes y Sigfried Giedion. Dentro de los profesores reformistas, tanto Alberto Cruz como Alberto Piwonka eran quienes estaban más familiarizados con los conceptos metodológicos vinculados a la enseñanza de los «Vorkurs» de la Bauhaus y la proyección de ellos en los EE.UU.

Si bien, en la Universidad de Chile los llamados «líderes espirituales» de la reforma, como Waldo Parraguez y Enrique Gebhard fueron importantes en la formulación del nuevo plan, ellos aún no formaban parte del cuerpo docente, y no participaron directamente en la Comisión que debatió institucionalmente la elaboración del nuevo Plan de Estudios, que se había formado a mediados de 1944. Ésta se constituyó bajo la dirección del Decano Hermógenes del Canto Aguirre, y contó con la presencia de los profesores Juan Martínez, Mauricio Despouy, Camilo Mori, Héctor Mardones Restat y José Aracena Aguilar, y los dirigentes del Centro de Alumnos, Abraham Schapira Spaisky y Gastón Etcheberry Orthus. Tuvieron también una participación importante del grupo reformista varios estudiantes de la escuela: Hernán Behm Rosas, Eduardo Preller Werner, Jaime Bendersky Smuclir, Miguel Lawner Steimann, Sergio González Espinoza y Julio Mardones Restat, todos contemporáneos en los primeros años de la escuela.

El plan de estudios de la Escuela de Arquitectura de la Universidad de Chile no había sufrido cambios significativos desde 1933. A pesar de los avances introducidos en ese año y el ingresos de los nuevos profesores, la estructura del plan de estudios hasta 1944 seguía atravesada por el academicismo, pese a los influjos de modernidad que podían ser visibles en los talleres de Juan Martínez, José Aracena, Roberto Dávila Carson y en algunos de los proyectos de título de la Escuela. La ambigüedad de la escuela en su malla curricular era evidente. Mientras que Martínez promovía en sus talleres el más estricto funcionalismo, Dávila Carson alentaba a sus estudiantes a ensayar de igual manera la arquitectura moderna o el denominado «estilo colonial chileno» ${ }^{26}$. Para el grupo de estudiantes reformistas esos talleres no representaban en lo más mínimo una posición de avanzada hacia las ideas más radicales de la modernidad. Sin duda, un contrapunto a esa ambigüedad lo constituía el taller de

21 Ver «Arquitectura: Escuela de Arquitectura de la Universidad de Chile» en Revista de Arte de la Facultad de Bellas Artes de la Universidad de Chile. Año 1 N 4 de $1934-1935$.

22 Ver «La Escuela de Ingeniería y la Escuela de Arquitectura de la Universidad de Chile: presentación fotográfica de Antonio Quintana», Zig-Zag, 1936.

23 Al concurso se presentaron cuarenta propuestas, cinco de las cuales participaron en la segunda etapa. En medio de una gran polémica fue declarado ganador el proyecto de Juan Martínez, quedando relegados dos proyectos de Valdés, Castillo, Huidobro, Piwonka, Siefer, Labarca y Domínguez, un proyecto de Pérez de Arce, Echenique, Besa y Tagle y un proyecto encabezado por Simón Perelman y su Taller de la Escuela de Arquitectura de la Universidad de Chile.

24 Emilio Duhart. Op. Cit. En entrevista inédita a Duhart de Fernando Pérez Oyarzún y Pilar Urrejola realizada en 1994.

25 Por reglas canónicas, en ese tiempo estaban prohibidas las huelgas en la Universidad Católica. Ante esto, la totalidad del alumnado de la Escuela de Arquitectura abandonó la universidad como acto de presión. La quema de los vignolas fue la acción simbólica con que se puso término al conflicto. Ver Eliash, Humberto y Moreno, Manuel. «La escuela moderna 1945-1967» en Strabucchi, Wren (Ed). Cien años de arquitectura en la Universidad Católica. Ediciones ARQ, 1994.

26 Bien sabido es que en el concurso que ganó para el restaurante Cap Ducal, había presentado varias propuestas en diferentes estilos, incluido «el moderno». Ver tesis de magíster de Macarena Cortés «Un nuevo espacio de veraneo y la metáfora naval: el Cap Ducal en la génesis de la modernidad», presentada en la Pontificia Universidad Católica de Chile en 2001. 


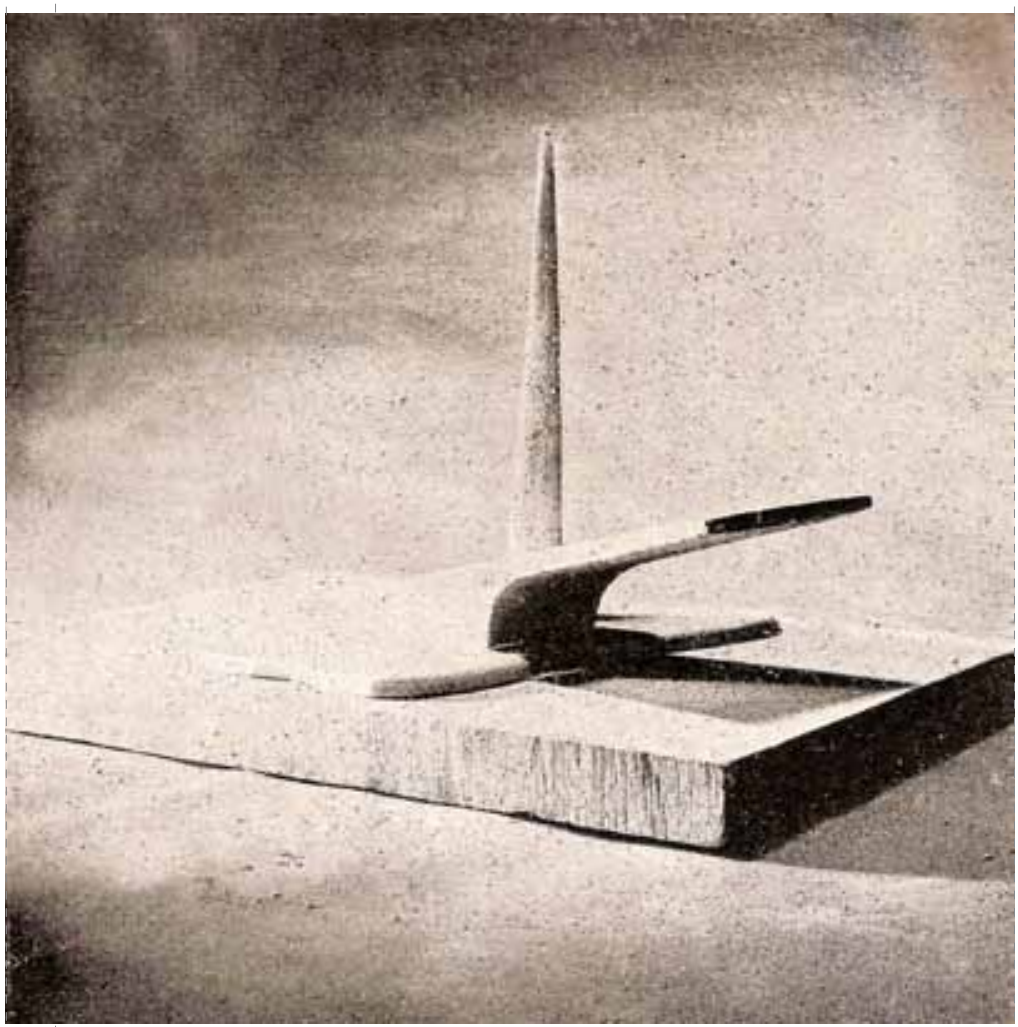

Catálogo Exposición cincuentenario Escuela de Arquitectura Universidad de Chile 1896-1946. Universidad de Chile, 1947. Trabajo de Alicia Drouilly en el curso de Plástica de Ventura Galván.

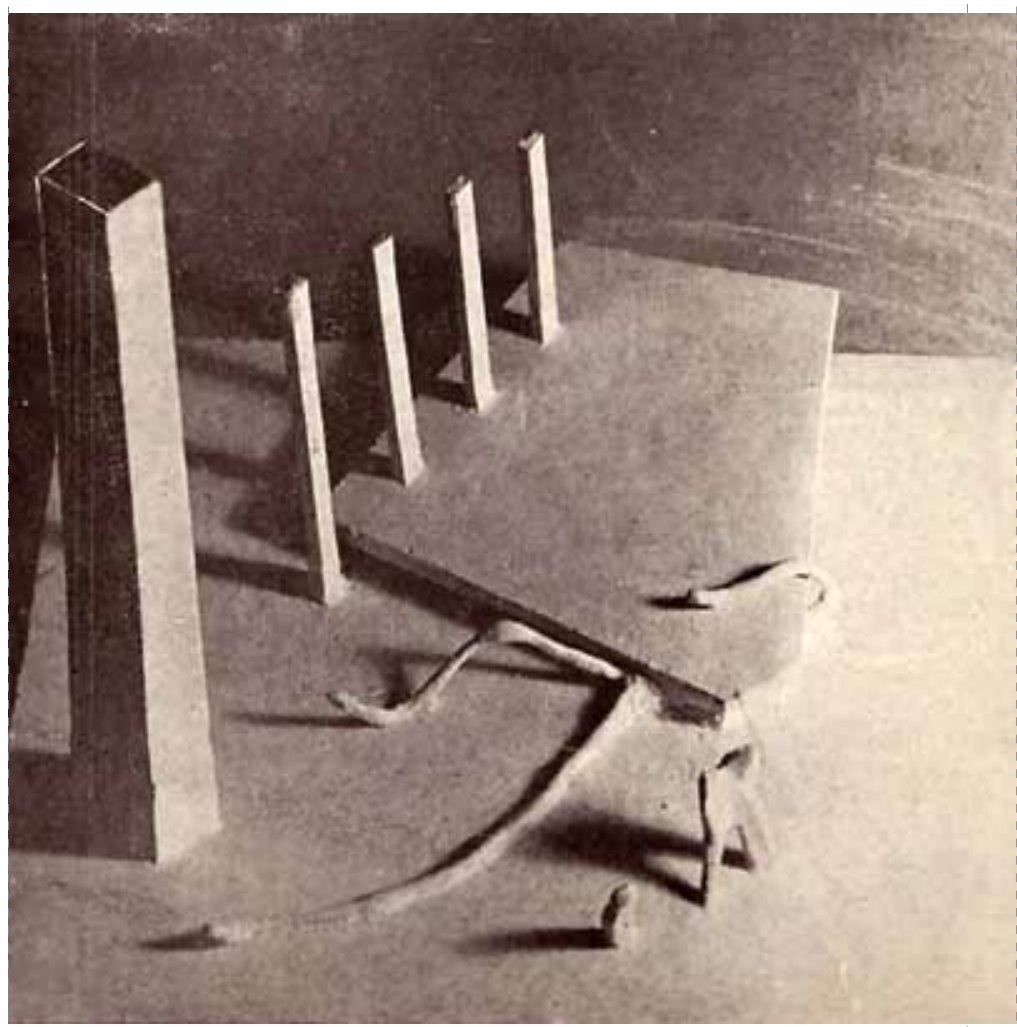

Catálogo Exposición cincuentenario Escuela de Arquitectura Universidad de Chile 1896-1946. Universidad de Chile, 1947. Trabajo de Carlos Martner en el curso de Plástica de Ventura Galván.
Despouy, profesor que había sido promovido en la Escuela poco antes de la reforma de 1946, y que tenía una de las más interesantes y consistentes trayectorias en la práctica profesional en el medio local.

Además de la influencia de Parraguez y Gebhard sobre el grupo reformista, fue importante el aporte del arquitecto húngaro Tibor Weiner Hirschfeld, quien había llegado a Chile en 1939. Según Daniel Talesnik «el aporte de Tibor Weiner a la reforma tuvo relación principalmente con el desarrollo del plan de estudios y los contenidos del mismo, su pasada por la Bauhaus de Meyer y su posterior trabajo en la Unión Soviética le habian dado una experiencia sin parangón para el medio chileno y lo convertían en alguien idóneo para ayudar a los líderes de la reforma a materializar sus objetivos ${ }^{27}$.Con posterioridad a la reforma será incorporado como profesor del primer año de la Escuela de Arquitectura.

\section{Si bien la renovación de los talleres} representaba una de las necesidades más urgentes que la Escuela debía subsanar, no menos importante era incorporar la plástica moderna en el centro de la formación inicial de la carrera. Antes de esta reforma la plástica no formaba parte del currículo de primer año y no estaba orientada hacia lo abstracto. En años anteriores se enseñaba un curso de Plástica, que dictaba desde 1926 el escultor de origen francés Hipólito Eyraud Escobar. Eyraud es conocido por su participación en los motivos decorativos y en la ornamentación de uno de los edificios más característicos del BeauxArts en Santiago, la Biblioteca Nacional, del arquitecto Gustavo García Postigo.

\section{El curso de plástica de Ventura Galván y el grupo Plástico}

Uno de los cambios más significativos en el currículo del primer año luego de la reforma de 1946, fue la incorporación del taller de Plástica encabezado por Ventura Galván. Su curso venía no sólo a reemplazar el curso de Eyraud, sino que complementaba el que dictaba hacía más de una década Camilo Mori.

A pesar de que el curso de Dibujo y Colorido no estaba formalizado en el nuevo currículo, la permanencia de Mori en la Escuela era importante para el grupo reformista, ya que, además de haber sido un apoyo importante como miembro de la comisión que estudió el nuevo Plan de Estudios, era un reconocido pintor de avanzada, conocedor de los

27 Talesnik, Daniel. Op. Cit. En «Tibor Weiner y su rol en la reforma: una re-introducción», en revista De Arquitectura N 14 segundo semestre de 2006. p. 67. 
problemas plásticos modernos. Luego de la reforma, Mori reorientó su curso hacia la composición moderna, parte fundamental del Taller Elemental que compartió con Galván en los primeros años de la carrera ${ }^{28}$.

Tanto el curso de Plástica de Galván, como el de Composición de Mori y el de Dibujo Técnico de Victoria Maier formaban en el ciclo inicial de la carrera el denominado taller Elemental. En él se enseñaban los aspectos inherentes a la plástica moderna y la composición. El nuevo reglamento de la Escuela de Arquitectura en 1946 detalla los objetivos del nuevo plan en cada una de sus áreas ${ }^{29}$. A propósito del taller de Composición, se señalaba que el curso... "plantea el problema plástico en el terreno de la abstracción pura como principio, en grado creciente de complejidad. Aborda el problema de la verificación de los problemas geométricos y los trazos reguladores de la composición» ${ }^{30}$ Respecto al taller de Plástica, el mismo documento señala que "presenta un desarrollo paralelo al taller de Composición, avanzando desde la plástica por iniciación simple en una superficie, hasta la plástica de los volúmenes a través del contacto con distintos materiales. Se quiere hacer de estos ejercicios de plástica, una herramienta efectiva en la concepción del arquitecto» $^{31}$

El curso de Galván propiciaba una aproximación inicial a los problemas plásticos en base a la realización abstracta de conceptos básicos de orden, subordinación, relación y articulación entre distintos elementos. Su propuesta académica se basaba en una original innovación pedagógica que estaba guiada por la intuición y que resulta visible en el repertorio de ejercicios que se conocen ${ }^{32}$

La influencia de Galván se extendió con fuerza entre los estudiantes de la Escuela de Arquitectura y la Escuela de Artes Aplicadas. Un hecho significativo del legado de su taller fue la formación del grupo Plástico, que surgió en la Escuela de Arquitectura bajo su liderazgo y tutela en $1948^{33}$. El grupo organizó actividades y exposiciones en que se mostraban los resultados del trabajo del taller Elemental y en él participaron varios de los estudiantes de la generación de los reformistas: Sergio González, Miguel Lawner, Carlos Martner García, Juan Parrochia Begin, Osvaldo Cáceres González, Carlos Albrecht Viveros, Bernardo Trumper Roñis, Ricardo Tapia Chuaqui, Gonzalo Mardones Restat Ramón Méndez Brignardello, Alejandro Rodríguez Urzúa y Ana María Barrenechea Grünwald, entre otros. La revista ARQUITECTURA y Construcción (1945-1950) recogió la información de la primera exposición del grupo. En ella se compilan algunas de las impresiones de la prensa: "Las composiciones volumétricas son indudablemente lo más interesante desde el punto de vista del profesional arquitecto; aquí se plantean problemas de estructura, material y forma, que deben resolverse en un todo armonioso ${ }^{34}$. En la revista PRO ARTE (1948-1956) se hizo referencia a la misma exposición del grupo: "la reforma total del plan de estudios de la Escuela de Arquitectura de la Universidad de Chile, que se generara el año 1945, ha provocado un nuevo espíritu en el alumnado, que lo ha llevado, dentro del terreno de la plástica general, a investigaciones para su aplicación en Arquitectura... Este grupo Plástico representa la vanguardia y avanzada de la Escuela, el espíritu de renovación y reforma dentro de nuestra juventud de arquitectos, y su primera exposición justifica plenamente esta suposición ideológica, pues en esta exposición hay una auténtica manifestación de las inquietudes y problemas científicos y artísticos que a este grupo de jóvenes alumnos de la Escuela conmueven y preocupan» ${ }^{35}$

Aunque aparece escuetamente difundido su trabajo en ARQUITECTURA y CONSTRUCCIÓN, el grupo extendió con más fuerza su influencia en Pro ArTE, donde se hizo cargo de una sección dedicada a la arquitectura, con un marcado sesgo en la plástica. Ahí se publicó no sólo la información sobre el grupo y las exposiciones de la Escuela de Arquitectura, sino que referencias al trabajo y artículos de Naum Gabo, Ernesto Rogers, Serge Ivan Chermayeff y Moholy-Nagy.

\section{Раггаguez, Dvoredsky \\ y Galván en la práctica \\ profesional de la \\ arquitectura}

Las ideas de Parraguez y Dvoredsky sobre la plástica moderna ratifican el interés de su generación en introducir tempranamente en el debate arquitectónico los conceptos provenientes del arte abstracto y su relación con la arquitectura, en un ánimo de alimentar con nuevas referencias el proceso creativo, a través de criterios y propósitos proyectuales. A pesar del reconocido trabajo plástico que realizaron en el marco de la experiencia Decembrista, ellos no parecen haber conseguido trasladar esas ideas al ámbito de la enseñanza. Finalmente, luego de la reforma de 1946, sus actividades docentes se dirigirán hacia el Urbanismo, en el caso específico de Parraguez, y ambos como profesores en los talleres de Composición Arquitectónica en la Escuela de Arquitectura de la Universidad de Chile.

Parraguez, y en mayor medida Dvoredsky, pudieron materializar parcialmente las ideas provenientes de la plástica en sus proyectos de arquitectura. No es de extrañar como Dvoredsky manifestará que, en relación a su quehacer arquitectónico, «busqué, y busco, un equilibrio o armonía entre la racionalidad y la intuición. La expresión "J'aime l'emotion qui corrige la règle" estuvo frente a mí, desde mi juventud. Fue este concepto, y la necesidad de integrar lo abstracto y lo concreto, lo que me hicieron arquitecto, aún cuando dibujo, pinto y hago escultura... Los conceptos abstractos de dimensión, escala, proporción, orden, estuvieron siempre ligados a las muy concretas necesidades de estructura, instalaciones y edificación » ${ }^{36}$. En proyectos como el Teatro Dante, los edificios de renta en Santa Magdalena o en varias viviendas

28 Ver Barrenchea, Ana María et al. La reforma de 1946 en la Escuela de Arquitectura de la Universidad de Chile. Inédito, 1999.

29 Ver Centro de Estudiantes de Arquitectura Universidad de Chile. «Escuela de Arquitectura. Reglamento General: Segunda parte del informe de la comisión designada por el honorable consejo para estudiar la reforma de la enseñanza de la arquitectura», 1946.

Ídem.

30 lem.

31 Ídem.

32 Ver Catálogo Exposición cincuentenario Escuela de Arquitectura Universidad de Chile 1896-1946. Universidad de Chile, 1947. Este catálogo presenta una selección de trabajos de la Escuela.

33 La formación del grupo Plástico y la conducción de Galván está referenciada en el texto de Ana María Barrenechea «Tiempos de crítica y cambio». En el libro OcHo ARQUiTectos EN LA MEMORIA, Fundación Espacio y Desarrollo, 2005.

34 Ver revista Arquitectura y Construcción No 13 junio de 1948. p. 18

35 Ver revista Pro Arte Año I No 9 , jueves 9 de septiembre de 1948. p. 6

36 Tomada de Munita L, Hernán. «José Dvoredsky: reparando el olvido» en revista de Arquitectura Nº 14. Facultad de Arquitectura y Urbanismo Universidad de Chile, segundo semestre de 2006 
unifamilares es posible constatar parte de esas intenciones ${ }^{37}$. Con una trascendencia más reconocida que Dvoredsky en el ámbito de las ideas se encuentra la figura enigmática de Parraguez. Sin duda será un activista relevante de la nueva arquitectura, gracias a su influencia en la enseñanza, su vuelo en la plástica, la crítica y en áreas como el urbanismo y la vivienda. Dejó pocas obras construidas, en parte esto puede ser entendido por su prematura muerte sucedida en 1947. Quizás la más recordada sea la llamada casa 5.000, un centro de esparcimiento que formaba parte de la población Arauco y la casa Ortúzar en la calle Constitución ${ }^{38}$ Menos conocido fue el proyecto de Parraguez junto a Manuel Palma para el nuevo Estadio Universitario de la Universidad de Chile. Es una labor pendiente para la historiografía de la arquitectura moderna en Chile, profundizar en su pensamiento y obra.

Ventura Galván desarrolló una larga carrera académica vinculado a la Escuela de Arquitectura y la Escuela de Artes Aplicadas de la Universidad de Chile, tanto en Santiago como en Valparaíso ${ }^{39}$. Su carrera como arquitecto será particularmente interesante. Aunque sus obras construidas no fueron muchas, ellas se caracterizaron por un alto rigor compositivo e innovación técnica, fruto probablemente de esa manera de hacer las cosas que provenía del entendimiento de los criterios y conceptos de la plástica, que se transfieren en las decisiones del proyecto. Su dedicación a las obras fue significativa en todas las instancias del proyecto. No resulta extraño que sus obras más destacadas hayan sido encargadas dentro del ambiente universitario. Su obra más significativa posiblemente fueron los nuevos talleres de la Escuela de Artes Aplicadas en Cerrillos. Es llamativo además constatar que el resto de las obras de Ventura Galván hayan sido encargadas por artistas que eran sus compañeros de labores en la Escuela de
Artes Aplicadas. De esos vínculos académicos surgirán proyectos como la casa del escultor Juan Egenau y la diseñadora Rebeca Pérez Vial, la casa para el escultor Raúl Vargas Madariaga, la casa para Nora Pizzi Pozzi, la casa de la familia Strobel en El Arrayán y la casa de José Perotti en El Quisco. Además de las dos etapas de su propia casa en calle Granada. El conjunto de su obra arquitectónica, si bien parece ser escueto en cantidad, es de un alto valor plástico y calidad espacial.

Para este grupo de arquitectos y para muchos que formaron durante sus vidas, la plástica se constituyó en el eje vertebral de su quehacer académico y en un interés que traspasaban al ejercicio de la práctica profesional. Las aproximaciones puntuales que se conocen de sus trabajos en el campo de la plástica, se caracterizan por la intuición de sus propuestas y la experimentación que generaron en el ámbito de la disciplina, asumiendo el lenguaje abstracto para resolver los problemas de la forma. Las realizaciones plásticas de Parraguez, Dvoredsky o Galván atestiguan un proceso innovador en el ámbito del entrenamiento visual de la arquitectura. Ellos se aventuraron en caminos que parecían infranqueables, debido al peso de las tradiciones académicas o a las barreras culturales de su tiempo. Sus experiencias pueden ayudar a entender mejor el origen de los cruces que se proponían entre el arte y la arquitectura, que acompañaron las ideas en torno a las reformas curriculares en las escuelas de Arquitectura y el pulso de la profesión.

\section{Referencias bibliográficas}

Barrenechea, A.M. "Tiempos de crítica y cambio». Libro «Ocho arquitectos en la memoria». Fundación Espacio y Desarrollo, 2005.

Cáceres, G. «Nexos olvidados en la historia de la vanguardia chilena: de los Decembristas a la revista ARQuitectura». Revista $A R Q N^{\circ} 33$, agosto de 1996.

Castillo, Eduardo (Editor). «Artesanos, artistas, artífices: la Escuela de Artes Aplicadas de la Universidad de Chile 1928-1968». Ocho libros y Pie de texto, 2010.

Eliash, H; Moreno, M. «La escuela moderna 19451967» en Strabucchi, Wren (Ed). Cien años de arquitectura en la Universidad Católica. Ediciones ARQ, 1994

Estela, C; Padilla, J. I. «Amour à Moro: homenaje a César Moro». Lima, 2003

Haramoto, E. «Acuarelas de Ventura Galván Llorente». Revista De Arquitectura N² 2 Facultad de Arquitectura y Urbanismo Universidad de Chile, septiembre, 1991.

Lizama, P. «Escritos de Arte: (1925-1929) / Jean Emar». Dirección de Archivos y Museos y Instituto Barros Arana, 1992

Lizama, P. «Juan Emar y Vicente Huidobro: recuerdo y vigencia» en Monasterios P., Elizabeth (Editora). "Con tanto tiempo encima: aportes de literatura latinoamericana en homenaje a Pedro Lastra». Plural Editores, Bolivia, 1997.

Maúlen, D. «Experiencias docentes: inclusión / exclusión del espacio urbano y social 1933/1945/1967». Revista De Arquitectura $N^{\circ} 14$, Facultad de Arquitectura y Urbanismo Universidad de Chile. Segundo semestre del 2006.

Montecinos, H. «Ventura Galván y su aporte a la arquitectura chilena», en Boletín FAU año $4 \mathrm{~N}^{\circ}$ 3, 1991.

Munita L, H. «José Dvoredsky: reparando el olvido». Revista De Arquitectura No 14, Facultad de Arquitectura y Urbanismo, Universidad de Chile. Segundo semestre del 2006.

Parraguez, W. «Ensayo sobre plástica moderna». Revista ARQuitectura № 1 de 1935.

Rojas Mix, M. «Vicente Huidobro y el arte abstracto». Revista Araucaria de Chile $N^{\circ} 32$ cuarto trimestre de 1985

Talesnik, D. «Tibor Weiner y su rol en la reforma: una re-introducción». Revista De Arquitectura No 14, Facultad de Arquitectura y Urbanismo, Universidad de Chile. Segundo semestre del 2006.

37 Ver «José Dvoredsky R.» En Boletín del Colegio de Arquitectos correspondiente al primer semestre - mayo de 1954

38 Ver «Casa Ortúzar». En revista Urbanismo y Arquitectura N 1, mayo de 1939.

39 Probablemente los únicos textos publicados sobre la vida de Ventura Galván sean el discurso de Edwin Haramoto y el artículo de Hernán Montecinos. Ver Haramoto, Edwin. "Acuarelas de Ventura Galván Llorente», en revista De Arquitectura N o 2 de septiembre de 1991, pp 76-79. Montecinos, Hernán. «Ventura Galván y su aporte a la arquitectura chilena», en Boletín FAU año 4 № 3, 1991. Un aporte reciente al conocimiento de la labor de Galván en la Escuela de Artes Aplicadas es el libro de Eduardo Castillo Espinoza. Ver Castillo, Eduardo (Editor). Artesanos, artistas, artífices: la Escuela de Artes Aplicadas de la Universidad de Chile 1928-1968. Ocho libros y Pie de texto, 2010. 